\title{
Editorial
}

\section{Ética en tiempos de pandemia}

\section{Psicoanálisis, cine y respuestas singulares a lo fucked up del lazo social}

\author{
Juan Pablo Duarte", Lorena Beloso, Juan Ernesto Brodsky, Eugenia Destéfanis, \\ Gigliola Foco, Paula Mastandrea y Eugenia Castro
}

Universidad Nacional de Córdoba, Universidad de Buenos Aires, Argentina

The end of the fucking world es el título de una serie británica que se lanzó en el Reino Unido hacia fines de 2017, a menos de un año de comenzado el complejo proceso que concluirá en la salida de este país de la Unión Europea. El Brexit no es el fin del mundo pero es el fin de un modo de hacer mundo.

Como otros mundos que están en este, la Unión Europea comenzó con un discurso. En septiembre de 1946, desde el balcón de la Universidad de Zúrich, Winston Churchill llamó a las principales potencias mundiales a ¡Levantar Europa! "Levantar" significaba en este contexto unir países en el ideal de una gran familia próspera y feliz que transforme las diferencias que habían conducido a la Segunda Guerra Mundial en la posibilidad de compartir una herencia común. Setenta años después, el Brexit podría leerse como uno de los signos que anuncian el fin de esa concepción del mundo. Lejos de responder a lo fucked up del lazo social, los semblantes del mundo contemporáneo están a su servicio. La producción, cálculo algorítmico y uso político del miedo, el odio o el rechazo al semejante determinan las formas que asume lo colectivo en la actualidad en mayor medida que los ideales colectivos. Gisela Smania lo destaca con precisión en su lectura del film Brexit: The Uncivil War, dirigido por Toby Haynes. En Elogio a lo imposible de calcular, la ética del psicoanálisis permite a la autora articular en la autorización en el decir la posibilidad de un lazo social en el que se reconozca lo singular en este contexto de lo colectivo. No se trata de un planteo utópico sino de la praxis “a la altura de las circunstancias" que hace posible la forma lógica del objeto a propuesta por Jacques Lacan. La lectura de un lazo social posible en The End of the F***ing World impulsa también La herejía de cada uno y el amor como escritura, frente a la pandemia del Uno solo. A partir de esta serie británica inspirada en un cómic Charles Forsman, Claudia Lijtinstens aborda la singular historia de amor de dos jóvenes que logran hacer de su desengaño al Otro una insumisión herética que les permite salir del autoerotismo del Uno sólo, una pandemia contemporánea que promueve el aislamiento con anterioridad a la emergencia del COVID-19.

A la línea de reflexión ética en tiempos de pandemia que propone este número se suman tres artículos atravesados por el abordaje y las respuestas ante los modos de emergencia de la segregación en la actualidad. En Ese intimo desconocido, a partir de la lectura de series como Black mirror, The Handmaid's Tale y Little fires everywhere, Celeste Viñal destaca las posibilidades desidentificatorias de la práctica psicoanalítica en cuyos efectos se verifica el reconocimiento de las propias, íntimas y desconocidas tendencias segregativas que porta cada sujeto. A través de Dallas Buyers Club, Joaquín Carrasco aborda una respuesta al rechazo al otro en el contexto de la epidemia del SIDA a mediados de los ochenta. La ficción de un goce común de los cuerpos que impulsa la serie Sense 8, creada por las hermanas Lily y Lana Wachovsky, permite a Micaela Parici leer una ficción que

juanpduarte2@eco.uncor.edu 
pone en escena la insoportable extrañeza que habita en la extimidad de cada uno.

Para conversar en torno al tema del presente número, el equipo del Journal Etica E Cine se conectó con Gustavo Dessal, psicoanalista miembro de la Asociación Mundial de Psicoanálisis que ejerce su práctica en Madrid. Respecto a la Ética en tiempos de pandemia, Dessal se refirió a la apertura de una nueva etapa en la discusión de la práctica del psicoanálisis en un contexto donde prima lo virtual. Además, hacia el final de la entrevista podrán leer una lúcida referencia a Zootopia, el film de animación producido por Walt Disney Animation. A modo de un sueño, Dessal extrae de la comunidad de Zootopía un mensaje transversal a los diferentes artículos de este número. La alteración de los equilibrios de la vida comunitaria produce un modo de emergencia inédita de lo diverso que anida en cada uno y con ello el desafío de lograr una convivencia que trascienda cualquier ideal de armonía. Desde los principios éticos que le son propios, la práctica del psicoanálisis tiene la posibilidad de responder a este desafío a partir de la rectificación en el uno por uno de los sujetos que atraviesan la experiencia.

El diálogo entre psicoanálisis, ética y cultura en el contexto del lazo social que plantea la pandemia está presente también en la entrevista a Edgardo Castro. El cineasta argentino brinda una reflexión aguda sobre la soledad y los vínculos, ejes centrales de sus últimas obras cinematográficas La noche (2016), Familia (2019) y Las ranas (2020). Retomando la idea de que el cine es algo que nos pasa, Castro propone pensar la pandemia como oportunidad para la experiencia singular, para abrir preguntas en lugar de buscar certezas.

Como cierre del presente número, el lector podrá encontrar la reseña del libro The wire. La serie-sintoma, editado por la Editorial Universitaria de la Universidad Nacional de Córdoba en la que se destaca el encuentro y anudamiento entre la teoría psicoanalítica y la reflexión en torno a la ciudad contemporánea a partir de esta serie de TV de culto. A esta reseña se suma la de Hay tantas fes, el último número de Lapso, la revista de la Maestría en Teoría Psicoanalítica Lacaniana de la U.N.C que actualiza la discusión en torno al posible triunfo de la religión al que se refirió Jacques Lacan en 1974.

Ética en tiempos de pandemia es un número del Journal Ética E Cine producido en un contexto inédito de nuestra civilización que conserva el espíritu que impulsa cada uno de sus números: transformar el cine y las series de TV en una matriz para reflexionar sobre tiempo que nos toca vivir. 